\title{
Rheumatoid arthritis, the contraceptive pill, and androgens
}

\author{
William H James
}

\begin{abstract}
Summary
Evidence is accumulating that low androgen concentrations are a cause of rheumatoid arthritis. This would explain a number of established features of the epidemiology of the disease. These include: $(a)$ the variation of disease activity with pregnancy; (b) the variation of age at onset by sex; (c) the variation by sex with HLA-B15; (d) the association with bone mineral density; and $(e)$ the differing time trends in incidence rates by sex.

It is argued, moreover, that if one makes a plausible assumption-namely, that women who choose oral contraceptives have high androgen concentrations at the time they first make this choice-then an explanation becomes available for the confusion about the relation between rheumatoid arthritis and oral contraception. Grounds are adduced for that assumption.
\end{abstract}

If this line of reasoning is substantially correct it also has implications for the relations between rheumatoid arthritis and smoking and consumption of alcohol.

(Ann Rheum Dis 1993; 52: 470-474)

This paper consists of two parts. The first section reviews the evidence that a major cause of rheumatoid arthritis (RA) is the presence of low androgen concentrations. If this hypothesis were true, a number of features of the epidemiology of the disease would be explained. In the second part it is argued that this hypothesis, together with a plausible assumption, explains the confusion about the relation between RA and oral contraception.

Angrogen concentrations and rheumatoid arthritis

There can be no reasonable doubt that patients with RA have lower mean androgen concentrations than controls; this is so for both male $^{1-4}$ and female ${ }^{5-12}$ patients. Findings for female patients are less decisive, however, and clearly, one reason for this is that the published data relate to samples that are too small. Spector et al published data on the serum testosterone concentrations of 87 male patients and 141 controls. ${ }^{1}$ The ratio of the mean difference in testosterone concentrations to the standard deviations in these data is about $3 / 5$. Standard power analysis ${ }^{13}$ indicates that to stand eight chances in 10 of detecting such a difference-if it exists in female samples-at the 0.05 level, one would need equal sized samples (of patients and controls) each numbering about 40. As far as I know there have been seven studies on androgen concentrations in female patients with RA. ${ }^{5-12}$ (The data in references 6 and 7 seems to refer to the same patients. ${ }^{6}$ ) The respective numbers of female patients with RA in each of the seven studies were $21,10,16,8,31,77$, and 49 , so it is perhaps not surprising that no clear pattern has emerged. Five of these studies provided evidence of low androgen concentrations, however, and in four the difference was reportedly significant. Cumulatively the significance of these data is overwhelming. (The Poisson probability of four or more events out of seven being significant by chance at the 0.05 level is less than 0.0005 .)

At first sight it is not clear whether these low androgen concentrations may be a consequence or a cause of the disease. Recent work, however, strongly suggests that they are a cause.

HLA ANTIGENS AND MALE PATIENTS

There are grounds for suggesting that HLA antigens act as markers for disease by indexing testosterone concentrations, which are pathologically high in the case of B27 associated diseases and pathologically low in the case of B8 associated diseases. ${ }^{14} 15$ Rheumatoid arthritis has been shown to be associated with B15: in particular, the gene is significantly more common in male patients than in female patients or controls. ${ }^{16}{ }^{17}$ Ollier et al gave two independent rankings of men's mean testosterone concentrations by 12 HLA antigens at the $\mathrm{B}$ locus. ${ }^{18}$ In each ranking $\mathrm{B} 15$ had the lowest rank. The probability that this is due to chance is one in 144 . The present line of reasoning indicates that the low mean testosterone concentrations in male patients with RA may be a genetically determined precursor rather than a consequence of the disease. Indeed, these data strongly support the hypothesis that low testosterone concentrations are a cause of RA in men. This conclusion is further supported by the improvement of male patients after androgen treatment (admittedly selected for low testosterone concentrations). ${ }^{19}$

HLA ANTIGENS AND FEMALE PATIENTS

It is well established that another gene which is more common in many samples of patients 
is HLA-DR4. Deighton et al reported that this gene is associated with low free testosterone in both healthy women and postmenopausal women with RA. ${ }^{20}$ Using Fisher's method, ${ }^{21}$ it may be calculated that the joint two way significance of these two test results is $0 \cdot 07$. So if a one way test is used, as is appropriate in testing against the present directional null hypothesis (that DR4 is not associated with lower testosterone concentrations), the data achieve formal significance. Using the same logic as used above, one can infer that DR4 is associated with low testosterone, which causes RA in (postmenopausal) women.

I know of no data on the mean testosterone concentrations of women with B15. Although the testosterone concentrations of both men and women are associated with HLA markers, the same markers are apparently not equally associated with testosterone in the two sexes. For instance, B27 is apparently associated with high concentrations of testosterone in men but not in women, ${ }^{14}$ and B8 is associated with low testosterone concentrations in women ${ }^{22}$ but apparently not in men. ${ }^{18}$ (This may be because the HLA genes index gonadal size, ${ }^{23}$ and that though the main sources of testosterone in men are the testes, in women they are the adrenal glands.) It seems reasonable therefore to propose that B15 is not as powerfully associated with low testosterone concentrations in women as in men, and may not be associated at all. This, if I am correct, would explain the hitherto unexplained differing strengths of the associations of B15 with RA in men and women.

In the following sections it will be indicated how the hypothesis accommodates some well established features of the epidemiology of RA.

\section{The hypothesis and the epidemiology of RA} RHEUMATOID ARTHRITIS AND PREGNANCY More than $75 \%$ of pregnant patients improve, with the maximum improvement being in the third trimester. Some weeks to months after delivery a flare up occurs in more than $90 \%$ of these patients. ${ }^{24}$ Such observations have often prompted the following question. If the higher incidence of RA in women than men has a hormonal basis, why does pregnancy (which is accompanied by a surge of female hormones) not exacerbate rather than ameliorate the disease? The answer, according to the hypothesis, is that the disease is caused by low concentrations of male hormones and not high concentrations of female ones. Thus amelioration during pregnancy is due to the increasing quantities of androgens produced by the corpus luteum, placenta, and fetal testes and adrenal glands. ${ }^{25}$ Relapse after parturition is, according to the hypothesis, due to withdrawal of these androgens.

AGE AT ONSET OF RHEUMATOID ARTHRITIS BY SEX

More women than men have clinical RA. The sex ratio of patients varies by age at onset, however. Goemaere $e t a l^{26}$ reported that among their patients with onset before the age of 30 the ratio of women to men was $3 \cdot 7: 1$; this number declined with increasing age of onset, and among these with onset after the sixth decade of life there were equal numbers of men and women.

The regressions of free testosterone concentrations on age are very different in men and women. In men the mean concentration declines roughly linearly from about the age of 30 onwards, and the decline is about fivefold between the ages of $30-39$ and 80 and older. ${ }^{27}$ In women, in contrast, mean free testosterone concentrations reportedly decline between 30 and 50 but apparently rise thereafter ${ }^{28}$ Schiff has reported a relative androgen excess in postmenopausal women contrasted with women before the menopause. ${ }^{29}$ Thus if RA were partially dependent on free testosterone concentrations then the sex ratios of patients by age at onset might be explained by these differing regression patterns.

RHEUMATOID ARTHRITIS AND BONE MINERAL DENSITY

It has been reported that patients with $\mathrm{RA}$ have significantly lower bone mineral density than controls. ${ }^{30}{ }^{31}$ One cause of such a condition is low androgen concentrations. ${ }^{32} 33$ So I suggest that the association of RA with osteoporosis is secondary to associations of both with low androgen concentrations.

\section{SECULAR CHANGES IN THE SEX SPECIFIC}

INCIDENCE OF RA

Data from studies in the United States ${ }^{34}$ and Britain $^{35}$ indicate that the incidence of RA in women has declined over the past three decades, whereas that of men has been stable. These reports have prompted the suggestion that oral contraception may be responsible; in the next section it will be argued, however, that this is an unsatisfactory explanation. Kempers wrote that 'a new pride, self-regard and identification with a buoyant social force is women's heritage in recent years'. ${ }^{36} \mathrm{He}$ adduced powerful evidence to suggest that androgen concentrations in women have slowly increased in response to the successes of the Women's Movement. Accordingly, I suggest that the decline in the incidence of RA in women (but not men) has been due to a secular increase in androgen concentrations in women.

\section{Oral contraception and rheumatoid arthritis}

A number of recent studies on RA have focused on the possibility that the disease is affected by ingestion of oral contraceptives. Over the last decade a dozen large scale studies have offered strikingly dissimilar conclusions on this possibility. An international workshop was held in Leiden in 1989 in an attempt to reach a consensus. ${ }^{36 a}$ It is not unfair to comment that consensus proved evasive. 
More recently, Spector and Hochberg, having completed a meta-analysis on nine studies, found that the 'protective effect' of the contraceptive pill was less in current users than in past users. ${ }^{37}$ Accordingly they suggested that the effect of the pill may be to delay the onset of disease or to prevent progression to severe disease. Hannaford et al reported that (as in the general population) the incidence of $R A$ among former users and never users of the contraceptive pill had declined over the past two decades, whereas current users had not experienced this trend. ${ }^{38}$ This result may also - perhaps with some strain-be reconciled with Spector and Hochberg's suggestion that the contraceptive pill postpones disease.

Hazes and van Zeben have reviewed the overall unsatisfactory state of studies relating RA to the contraceptive pill..$^{39}$ I reproduce their observations, not with the promise that my suggestions will explain them all, but in the conviction that they illustrate the need for some new hypothesis. These authors noted:

1 Seven studies had shown a reduction of RA of about $50 \%$ in those using oral contraceptives, whereas five studies had reported no effect and one had been inconclusive.

2 Two meta-analyses had reported a slight protective effect; one result was significant and one not.

3 The studies in the US had calculated relative risks of about unity, whereas values for those studies from Europe were about $0 \cdot 5$.

4 Hospital based studies had generally shown significant effects, whereas population based studies had not.

Hazes and van Zeben concluded that it is increasingly being suggested that oral contraceptive use may in fact be a marker for some other causal factor'. ${ }^{39}$ Accordingly, I suggest that the factor for which the contraceptive pill is a marker is androgen concentrations. The suggestion is that $(a)$ low androgen concentrations are a cause of RA; $(b)$ women who choose oral contraceptions initially have higher androgen concentrations than other women; and (c) a pharmacological effect of oral contraceptives is to lower women's androgen concentrations.

If this set of propositions were true it might explain the disparities between the results mentioned above. The third proposition (c) is established, ${ }^{40}{ }^{41}$ and the first proposition (a) was dealt with in the first part of this article, so I shall now review the data on the second and these propositions $(b)$.

TESTOSTERONE CONCENTRATIONS OF WOMEN WHO CHOOSE ORAL CONTRACEPTIVES

I know of no direct data on the testosterone concentrations of women at the time they first choose to use oral contraceptives, but there are strong grounds for supposing them to be higher than those of other women, for the reasons given below.

In a variety of studies with human and animal subjects testosterone concentrations have been associated with dominance, aggression, antisocial behaviour, sensation seeking, persistence, and libido. ${ }^{42}$ In general, testosterone concentrations are associated with the same sorts of personality traits in the two sexes, ${ }^{43}$ and Udry and Talbert concluded that the effects of testosterone on personality are direct. They confirmed the finding of Baucom et $a l^{44}$ that women with high testosterone concentrations (as opposed to those with low testosterone concentrations) significantly more often describe themselves as 'enterprising'. Other adjectives significantly more often applied to themselves by women with high testosterone concentrations in one or the other of these studies were 'dominant', ${ }^{43}$ 'resourceful', ${ }^{44}$ and 'uninhibited'. ${ }^{44}$

Our overall understanding of the psychological effect of testosterone in women may be helped by reference to studies on testosterone concentrations in women by their occupation. Schindler found that women lawyers had higher testosterone concentrations than nurses, teachers, and athletes. ${ }^{45}$ Purifoy and Koopmans found that women managerial, technical, and professional workers had higher testosterone concentrations than clerical workers and housewives. ${ }^{46}$ Bancroft et al found higher testosterone concentrations in women who worked full time outside the home than in women who did not, and they suggested that women with high testosterone concentrations may be 'more likely to pursue careers and less likely to conform to the conventional stereotype of the "happily married women". 47 Morris et al reported that graduate students in their sample of married women had higher testosterone concentrations than other women. ${ }^{48}$ Lastly, Dongyun and Yumin reported significantly higher testosterone concentrations in women pilots than in women ground crew. ${ }^{49}$

It is useful to reflect on one of the problems faced by a young woman embarking on her sexual life. She needs determination and enterprise to confront a doctor to get a prescription for oral contraceptives. The younger she is, the more enterprise she will need. So it is noteworthy that among women using oral contraceptives, young women ${ }^{50}$ and those who have been taking oral contraceptives for only a short time ${ }^{51}$ have low estimated relative risks of RA. This is contrary to expectation based on the hypothesis that oral contraceptives have a true protective effect, and indeed supports the notion that the contraceptive pill is a marker for some other agent-here, according to my hypothesis, androgen concentrations. In short, there is reason for suspecting that women who choose oral contraceptives have higher testosterone concentrations than controls at the time of the choice. So there are good grounds for all three of the propositions outlined above.

\section{Research proposals}

1. As these three propositions could together explain the confusion in regard to the relationship between oral contraceptives and 
$\mathrm{RA}$, it is now important to test whether young women who choose the pill do indeed have higher testosterone concentrations than controls at the time of the choice.

2. It is also now important to accumulate further data on the progress of the disease in unselected male patients treated with androgens.

3. If the present line of reasoning were correct, it would imply that the amelioration in pregnancy would be greater in the presence of a male rather than a female fetus (because of the additional androgens secreted by the fetal testes). The point should be tested.

4. It has sometimes been suggested that patients with RA have a typical personality. ${ }^{52}$ The question arises whether this might be a consequence of the disease. If I am correct, this is not the complete answer. Instead, both the disease and (part of) the personality are consequences of low testosterone concentrations. This too might be subjected to testing.

5. The form of argument used above might have wider applications because there is at least one other agent which, like oral contraceptives, might be expected to be chosen disproportionately often by people with high testosterone concentrations and which is known to have the pharmacological effect of depressing testosterone. Alcohol and cigarettes might both be suspected of indexing high testosterone concentrations at the time of first use (because of their associations with sensation seeking)..$^{54}$ Alcohol certainly lowers men's testosterone concentrations. ${ }^{56}$ Whether smoking has the same effect is not clear because (as far as I know) all the relevant studies have contrasted samples of smokers with samples of non-smokers-thus failing to consider the presumption that smoking initially indexes high testosterone concentrations. (The association between smoking and low sperm counts $^{57}$ lends weight to the suspicion that it too lowers testosterone concentrations.) What is needed is a longitudinal study on the testosterone concentrations of smokers and of non-smokers. Until that is done, we shall not know for certain the effect of smoking on testosterone.

The relation between smoking and RA has been reported as significantly positive (exacerbating?) $^{58}$ and significantly negative (ameliorative?). ${ }^{59}$ The consumption of alcohol has been reported to have a negative association with the disease.$^{59}$ Interpretation of these findings must await research on the problems outlined above.

I am grateful to Dr P N Sambrook (Sydney, Australia) for sending me two useful references.

1 Spector T D, Ollier W E R, Perry L A, Silman A J, Thompson P W, Edwards A. Free and serum testosterone levels in 276 males: a comparative study of rheumatoid levels in 276 males: a comparative study of rheumatoid
arthritis, ankylosing spondylitis and healthy controls. Clin Rheumatol 1989; 8: 37-41.

2 Gordon D, Beastall G H, Thompson J A, Sturrock R D Androgenic status and sexual function in males with rheumatoid arthritis and ankylosing spondylitis. $Q \mathcal{F} \mathrm{Med}$ 1986; 60: 671-9.
3 Cutolo M, Balleari E, Accardo S, et al. Preliminary results of serum androgen level testing in men with rheumatoid of serum androgen level testing in men with
arthritis. Arthritis Rheum 1984; 27: 958-9.

4 Spector T D, Perry L A, Tubb G, Silman A J, Huskisson E C. Low free testosterone levels in males with rheumatoid arthritis. Ann Rheum Dis 1988; 47: 65-8.

5 Cutolo M, Balleari E, Giusti M, Monachesi M, Accardo S. Sex hormone status in women suffering from rheumatoid arthritis. F Rheumatol 1986; 13: 1019-23.

6 Dougados M, Mahoul K, Benhamov L, Amor B. Androgen plasma levels in female rheumatoid arthritis patients. Arthritis Rheum 1983; 26: 935-6.

7 Dougados M, Nahoul K, Benhamov L, Jungers P, Laplane $D$, Amor B. Étude des androgènes plasmatiques chez les femmes atteintes de maladies autoimmunes. Rev Rhum Mal Osteoartic 1984; 51: 145-9.

8 Feher K G, Feher T. Plasma dehydroepiandrosterone, dehydroepiandrosterone sulfate and androsterone sulfate levels and their interaction with plasma proteins in rheumatoid arthritis. Exp Clin Endocrinol 1984; 84: 197-202.

9 Masi A T, Josipovic D B, Jefferson W E. Low adrenal androgenic-anabolic steroids in women with rheumatoid arthritis (RA): gas-liquid chromatographic studies of decreased 11-deoxy-17-ketosteroid excretion. Semin Arthritis Rheum 1984; 14: 1-23.

10 Spector T D, Perry L A, Tubb G, Huskisson E C. Androgen status of females with rheumatoid arthritis. $\mathrm{Br} \mathcal{F}$ Rheumatol 1987; 26: 316-8.

11 Feher K G, Feher T, Merety K. Interrelationship between the immunological and steroid hormone parameters in the immumological arthritis. Exp Clin Endocrinol 1986; 87: rheumatoi

12 Sambrook P N, Eisman J A, Champion G D, Pocock N A. Sex hormone status and osteoporosis in postmenopausal women with rheumatoid arthritis. Arthritis Rheum 1988; 31: 973-8.

13 Cohen J. Statistical power analysis for the behavioral sciences. New York: Academic Press, 1977.

14 James $W H$. Sex ratios and hormones in HLA related rheumatic diseases. Ann Rheum Dis 1991; 50: 401-4.

15 James W H. HLA markers, hormones and disease. $\mathcal{f} \mathrm{Med}$ Genet 1991; 28: 358-9.

16 Ollier W, Venables P J W, Mumford P A, et al. HLA antigen association with extra articular rheumatoid arthritis. association with extra articular
Tissue Antigens 1984; 24: 279-91.

17 Jaraquemada D, Ollier W, Awad J, et al. HLA and rheumatoid arthritis: a combined analysis of 440 patients. Ann Rheum Dis 1986; 45: 627-36.

18 Ollier W, Spector T, Silman A J, et al. Are certain HLA haplotypes responsible for low testosterone levels in males? Dis Markers 1989; 7: 139-43.

19 Cutolo M, Balleari E, Giusti M, Intra E, Accardo S Androgen replacement therapy in male patients with rheumatoid arthritis. Arthritis Rheum 1991; 34: 1-5.

20 Deighton C M, Watson M, Walker D J. Rheumatoid arthritis, sex ratios, HLA-DR, and testosterone. Ann Rheum Dis 1993; 52: 244

21 Fisher R A. Statistical methods for research workers. 13th ed. London: Oliver and Boyd, 1958: 100

22 Gerenčer M, Tujić M, Kerhin-Brkljačić V, Kaštelan A. An association between serum testosterone level and HLA phenotype. Immunol Lett 1982; 4: 155-8.

23 Iványi $\mathrm{P}$, Hámpl $\mathrm{R}$, Stárka L, Micková $\mathrm{M}$. Genetic association between $\mathrm{H}-2$ gene and testosterone association between $\mathrm{H}-2$ gene and testosteron
metabolism in mice. Nature New Biol 1972; 238: 280-81.

24 Hazes J M W. Pregnancy and its effects on the risk of developing rheumatoid arthritis. Ann Rheum Dis 1991, 50: $71-2$.

25 Buster J E, Simon J A. Placental hormones, hormona preparation for and control of parturition and hormonal diagnostic of pregnancy. In: De Groot L J, Besser G M Cahill G F, et al, eds. Endocrinology Philadelphia: Saunders, 1989: 2043-73.

26 Goemaere S, Ackerman C, Geothals K, et al. Onset of symptoms of rheumatoid arthritis in relation to age, sex and menopausal transition. $\mathcal{F}$ Rheumatol 1990; 17: 1620-2.

27 Vermeulen A. Decline in sexual activity in ageing men correlation with sex hormone levels and testicular correlation with sex hormone levels
changes. 7 Biosoc Sci Suppl 1979; 6: 5-18.

28 Purifoy F E, Koopmans L H, Tatum R W. Steroid hormones and aging: free testosterone, testosterone and androstenedione in normal females aged 20-87 years. Hum Biol 1980; 52: 181-91.

29 Schiff I. Menopause. In: Becker K L, Bilezikian J P, Loriaux $\mathrm{D} \mathrm{L}$, et al. eds. Principles and practice of endocrinology and metabolism. Philadelphia: Lippincott, 1990: 826-34.

30 Laan R F J M, Buijs W C A M, Verbeek A L M, et al. Bone mineral density in patients with recent onset rheumatoid arthritis: influence of disease activity and functional capacity. Ann Rheum Dis 1993; 52: 21-6.

31 Hall G M, Hall M L, Ell P J, Perry L A, Doyle D V, Spector $T$ D. Bone density in postmenopausal rheumatoid arthritis (RA). Relationship with disease activity, steroid use and sex hormone levels. Arthritis Rheum 1991; 34 (suppl): $\mathrm{S} 178$.

32 Jackson J A, Riggs $M$ W, Spiekerman A $M$. Testosterone deficiency as a risk factor for hip fractures in men: a case deficiency as a risk factor for hip fractures in
control study. Am $7 \mathrm{Med} S c i$ 1992; 304: 4-8.

33 Schot L P C, Schuurs A H W M. Sex steroids and osteoporosis: effects of deficiencies and substitute osteoporosis: effects of deficiencies and substitute

34 Linos A, Worthington J W, O'Fallon M, Kurland L T. The epidemiology of rheumatoid arthritis in Rochester, 
Minnesota: a study of incidence, prevalence and mortality. Am ₹ Epidemiol 1980; 111: 87-98.

35 Hochberg $M$ C. Contrasting trends in the incidence and prevalence of rheumatoid arthritis (RA) in England and Wales 1970-82. Arthritis Rheum 1988; 31 (suppl 1): R34.

36 Kempers T D. Social structure and testosterone. London: Rutgers University Press, 1990: 143-4.

36a Female sex hormones and rheumatoid arthritis. Proceedings of an international workshop held at Leiden, The Netherlands, 20-21 March 1989. Br f Rheumatol 1989; 28 (suppl I)

37 Spector T D, Hochberg M C. The protective effect of the oral contraceptive pill on rheumatoid arthritis: an oral contraceptive pill on rheumatoid arthritis: an meta-analysis. F Clin Epidemiol 1990; 43: 1221-30.

38 Hannaford P C, Kay C R, Hirsch S. Oral contraceptives and rheumatoid arthritis: new data from the Royal College of General Practitioners' oral contraception study. Ann Rheum Dis 1990; 49: 744-6.

39 Hazes J M W, van Zeben D. Oral contraception and its possible protection against rheumatoid arthritis. Ann Rheum Dis 1991; 50: 72-4.

40 van der Vange $\mathrm{N}$, Blankenstein $\mathrm{MA}$, Kloosterboer $\mathrm{H} \mathrm{J}$, Haspels A A, Thijssen J H H. Effects of seven low dose combined oral contraceptives on sex hormone binding globulin, corticosteroid binding globulin and free testosterone. Contraception 1990; 41: 345-52.

41 Bancroft J, Sherwin B B, Alexander G M, Davidson D W, Walker A. Oral contraceptives, androgens and the Walker A. Oral contraceptives, androgens and the Sexulity of young women. I1.

42 Dabbs J M, De La Rue D, Williams P M. Testosterone and Dabbs J M, De La Rue D, Williams P M. Testosterone and
occupational choice: actors, ministers and other men. $f$ Pers Soc Psychol 1990; 59: 1261-5.

43 Udry J R, Talbert L M. Sex hormone effects on personality at puberty. F Pers Soc Psychol 1988; 54: 291-5.

44 Baucom D H, Besch P K, Callahan S. Relation between testosterone concentration, sex role identity and personality among females. I Pers Soc Psychol 1985; 48 : $1218-26$

45 Schindler G L. Testosterone concentration, personality patterns and occupational choice in women. Dissertation Abstracts International 1979; 40: 1411A. (University Microfilms No 79-19, 403.)

46 Purifoy F E, Koopmans L H. Androstenedione, testos- terone and free testosterone concentrations in women of various occupations. Soc Biol 1979; 26: 179-88.

47 Bancroft J, Sanders D, Davidson D, Warner P. Mood sexuality, hormones and the menstrual cycle: III. Sexuality and the role of androgens. Psychosom Med 1983 45: $509-16$.

48 Morris N M, Udry J R, Khan-Dawood F, Dawood M Y. Marital sex frequency and midcycle female testosterone. Arch Sex Behav 1987; 16: 27-37.

49 Dongyun S, Yumin W. Flight influence on the plasma level of sex hormones of women pilots. Milit Med 1990; 155 $262-5$.

50 Dugowson C. In Discussion. Br f Rheumatol 1989; 28 (suppl 1): 42-5.

51 Hazes J M W, Diikmans B A C Vandenbroucke J P, de Vries R R P, Cats A. Reduction of the risk of rheumatoid arthritis among women who take oral contraceptives. Arthritis Rheum 1990; 33: 173-9.

52 Anderson K O, Bradley L A, Young L D, McDaniel L K Wise C M. Rheumatoid arthritis: review of psychologica factors related to etiology, effects and treatment. Psychol Bull 1985; 98: 358-87.

53 Oberai B, Kirwan J R. Psychological factors in patients with chronic rheumatoid arthritis. Ann Rheum Dis 1988; 47: 969-71.

54 Daitzman R J, Zuckerman M, Sammelwitz P, Ganjam V. Sensation seeking and gonadal hormones. $\mathrm{f}$ Biosoc Sci 1978; 10: 401-8.

55 Daitzman R J, Zuckerman M. Disinhibitory sensation seeking and gonadal hormones. Personality and Individual seeking and gonadal hormon

56 Bertello P, Gurioli L, Gatte G, Pinna G, Angeli A. Shor term ethanol ingestion can effect the testicular response to single dose human chorionic gonadotropin in normal subjects. $\mathcal{F}$ Endocrinol Invest 1986; 9: 249-52.

57 Spira A, Ducot B, Jouannet P, Soumah A, Feneux D, Albert M. Smoking, alcohol and male fertility. In: Spira A, Jouannet P, eds. Human fertility factors. Paris: Colloque INSERM, 1982: No 103.

58 Vessey M P, Villard-Mackintosh L, Yeates D. Oral contraceptives cigarette smoking and other factors in relation to arthritis. Contraception 1987; 35: 457-64

59 Hazes J M W, Dijkmans B A C, Vandenbroucke J P, de Vries R R P, Cats A. Lifestyle and the risk of rheumatoid arthritis. Ann Rheum Dis 1990; 49: 980-2. 